\title{
UNA MIRADA POÉTICA SOBRE EL NACIMIENTO DE LA NOVELA: EL PRÓLOGO DE HEINRICH HEINE A UNA EDICIÓN ALEMANA DEL QUIJOTE
}

\author{
Berit Balzer \\ Universidad Complutense de Madrid
}

La editorial "Verlag der Classiker" de Stuttgart publicó, en 1837, una nueva traducción al alemán del Quijote, hecha anónimamente a partir de la versión francesa de Louis Viardot. Esta versión había aparecido pocos meses antes en J. J. Dubochet et Cie. de París con ilustraciones de Tony Johannot. Heinrich Heine, renombrado poeta y periodista alemán, en exilio voluntario y afincado en la capital francesa desde hacía seis años, escribió un incisivo prólogo de 22 páginas a esta reedición alemana, en donde explicaba su primer contacto con el Quijote, así como el impacto que le había causado la relectura de la obra en las diferentes etapas de su vida.

De dicho prólogo -una joya de la personalísima prosa heineana que debería hacerse accesible en su totalidad a los estudiosos cervantinos, dado el interés que pueden tener tan originales valoraciones - afirmaba Heine en una nota del 3 de mayo de 1837, dirigida a su editor Campe, que era «desgraciadamente lo peor que había [sic] escrito jamás»². Sin embargo, algunos críticos creen que el hecho de rebajar el valor de este prólogo fue uno de esos camuflajes que Heine gustaba de emplear respecto a su persona y su obra ${ }^{3}$. Su biógrafo Fritz Mende valoraba, con razón,

1.- Existe una traducción de Pedro Gálvez para su edición de $\mathrm{H}$. Heine, Los dioses en el exilio, Barcelona: Bruguera 1983.

2.- Heinrich Heine, Sämtliche Schriften (en adelante HHSS) vol. 4,877. I a traducción de todas las citas procedentes de la obra de Heine y de otras fuentes alemanas es nuestra.

3.- Por otra parte, Carl Adolf von Wachsmann, un comentarista de prensa contemporáneo de Heine, llegó a opinar lo siguiente: «QQué nos va a decir Heine sobre Cervantes que no se haya dicho cualquier persona sensata cien veces a sí misma? ¿Acaso conoce las costumbres españolas, conoce aquella nacionalidad tan singular - diríamos maravillosade un pueblo, de cuya novela más nacional se trata aquí? - Sólo en el caso de un conocimiento completo del tema puede darse un prólogo de peso que aporte nuevas perspectivas». Abend-Zeitung. Blätter für Literatur und bildende Kunst, 16 (24 de febrero de 1838). Reproducido en HHSS 6/II: 668-669. 


\section{UNA MIRADA POÉTICA SOBRE EL NACIMIENTO DE LA NOVELA}

este prólogo como «una de las confesiones más significativas y reveladoras» (Mende 1967: 46). El boletín de suscripción que acompañaba la nueva edición de Stuttgart ponía como reclamo el parentesco espiritual entre Cervantes y Heine:

¿Debemos decir algo más sobre el prólogo de H. Heine? Ėntre todos los literatos alemanes, ninguno tiene mayor vocación íntima para introducir la obra maestra de Cervantes de este modo en la nación alemana que alguien como Heine, en muchos aspectos estrechamente emparentado con Cervantes en lo espiritual (DHA X: 651).

Durante el Carnaval, en febrero de 1837, estando postrado en cama con gripe, Heine escribió el prólogo, lo que le sirvió de pretexto para excusar la supuesta mala calidad de algo que, en uno de sus típicos juegos de palabras, «acusaba la influencia de la influenza» (HHSS 4: 876). Según nos cuenta, redactó el prólogo «cumpliendo órdenes y por cscasez de dinero» (HHSS 4: 876), recibiendo, eso sí, por el manuscrito la entonces nada despreciable cantidad de mil francos. Pero lo curioso c interesante es que, a lo largo de sus comentarios sobre el Quijote y Cervantes, hace entre líneas una especie de autobiografía, al rememorar las diferentes reacciones e interpretaciones que provocó en él el Quijote según su edad y circunstancias vitales, lo cual confirma una vez más la universalidad de un clásico de la literatura y aporta un interesante dato acerca de su recepción en un joven genio que se hallaba culturalmente tan distante del contexto hispano.

Heine dejaba así constancia, además, de su incondicional identificación con Cervantes, tanto en posturas vitales como en influencias artísticas. Los Cuadros de viaje, crónicas noveladas de distintas "salidas" de Heine por Alemania y al extranjero (Inglaterra, Polonia, Italia), ni se inspiran en la Odisea ni en la trayectoria de los héroes de la así llamada novela de aprendizaje (Bildungsroman) - una tipología que desde el Wilhelm Meister de Goethe se consideraba típicamente alemana- sino en el Quijote, sobre todo debido al omnipresente tono humorístico de éste. Tal inspiración es patente en La ciudad de Luca, cuarta entrega de los Cuadros de viaje, con la siguiente constelación de personajes: el falso Marqués Gumpelino y su criado Hirsch Hyazinth, así como la escéptica Mylady y su cándida amiga Francesca. El único experimento del pocta Heine con la novela, El rabino de Bacherach (1840), es igualmente deudor con el modelo cervantino en cuanto a la pareja de protagonistas dialogantes, el rabino Abraham y el renegado Judah Abarbanel. Pero entre el primer contacto de Heine niño con el Quijote y su debate artístico con la técnica cervantina propiamente dicha mediaban unos treinta años.

El libro había caído en sus manos ya en su infancia, seguramente en traducción de Bertuch o Tieck $^{4}$, disponible la primera en Alemania desde el año 1775 y la segunda desde 1799-1801. Heine, nacido en 1797, debió de tener, por tanto, entre seis y diez años -algún crítico ha insistido en los trece-, ya que, según cuenta cl afectado: «fue el primer libro que leí después de haber entrado en la fase juiciosa de mi infancia y estar en versado lo indispensable en las letras» (HHSS 4: 151). Por las numerosas referencias a lugares concretos que aparecen en este prólogo cabe suponer que fue durante sus años de liceo en Düsseldorf, si bien es verdad que con el humorista Heine siempre resulta difícil delimitar cuántos de sus comentarios se deben a la vena poética del momento y cuántos a un genuino recuerdo juvenil, reconstruido para recrear la atmósfera y el estado de ánimo en que se produjo la recepción de la obra. Las primeras páginas del prólogo reproducen un texto que Heine ya había publicado en $1830 \mathrm{en}$ los Cuadros de viaje IV, en el capítulo XVI de La ciudad de Luca:

4.- De la traducción de Tieck dijo Heine en su ensayo crítico de 1833, La escuela romántica: «Debo elogiar todavía dos trabajos del Sr. Tieck con los que se ha ganado en especial el agradecimiento del público alemán. Se trata de sus traducciones de una serie de dramas ingleses de la época pre-shakespeareana y su traducción del Quijote. Físta es especialmente lograda, ya que nadie ha entendido la alocada grandeza del ingenioso hidalgo de la Mancha tan bien, ni la ha reproducido tan fielmente como nuestro excelente Tieck» (HHSS 3: 430). 


\section{BERIT BALZER}

Aún me acuerdo muy bien de aquel breve tiempo en que me escabullí de casa una buena mañana y me metí en el parque para allí poder leer sin estorbos el Quijote. Era un bonito día de mayo, la floreciente primavera estaba expectante a la luz matutina, recibiendo alabanzas del ruiseñor, su dulce lisonjero, y éste cantaba su canción tan ticrnamente acariciador, con un entusiasmo tan melodioso que se abrieron de repente los pimpollos más tímidos, las concupiscentes hierbas se besaron más deprisa con los primorosos rayos del sol y árboles y flores se estremecieron de puro gozo. Pero yo me senté en un vicjo banco de piedra cubierto de musgo, en la Avenida de los Suspiros, según la llaman, cerca de la cascada y regocijé mi pequeño corazón con las grandes aventuras del audaz caballero.

[...] Puesto que yo, todavía inexperto en la lectura, pronunciaba cada palabra en voz alta, los pájaros y los árboles, el riachuelo y las flores podían escucharlo todo, y porque esos inocentes seres naturales, al igual que los niños, no saben nada de la ironía del mundo, también lo tomaron todo completamente en serio y lloraron conmigo las penas del pobre hidalgo (HHSS 2: 522 y HHSS 4: 151).

El ingenuo muchacho que era Heine entonces tomó al pie de la Ietra $-o$, más bien, Heine prefirió recordarlo así- todos los sucesos narrados en este complejísimo texto; es decir, hizo una lectura - ¿,cómo iba a ser de otro modo?- del nivel primario y más literal de una novela estratificada que juega con el lector, como el juego de espejos de las Meninas de Velázquez, a través de planos reflectantes / reflejados ${ }^{5}$. El poeta nos confiesa:

Mi infantil candidez lo tomó todo completamente en serio; por muy en ridículo que quedara el desafortunado héroe, me pareció que debía ser así, que eso formaba parte de la heroicidad, que se rían de ti igual que de las heridas inflingidas a tu cuerpo, y lo primero me contrariaba en la medida en que sentía estas últimas en mi alma. Yo era un niño y no conocía la ironía que Dios ha creado junto con el mundo y que el gran poeta había imitado en su mundillo impreso, y podía verter las más cálidas lágrimas cuando el noble caballero, a cambio de su hidalguía, no cosechaba más que ingratitud y palos. Incluso un viejo roble hendido sollozó y la cascada sacudió con más vehemencia su blanca barba como si quisiera despotricar contra la maldad del mundo (HHSS 4: 151).

Los niños - fundamental diferencia con la sandez de Sancho-suelen tener un sentido noble y radical de la justicia. Las cosas son o no son buenas, o son blancas o negras, porque no han sido relativizadas todavía por las experiencias de la vida adulta, que pueden restar de lo ingenioso todo aquello que tenía de ingenuo:

Opinábamos que el ánimo heroico del caballero no merecía menos admiración por el hecho de que el león le hubiese dado la espalda, sin ganas de luchar, y que sus hazañas eran tanto más elogiables cuanto más débil y reseco su cuerpo, cuanto más frágil la armadura que le protegía y cuanto más mísero el rocín que montaba. Despreciábamos a los bribones que, agasajados con abrigos de seda encarnada y provistos de frases altisonantes y títulos de duque, se burlaban de un hombre tan superior a ellos en fuerza de espíritu y magnanimidad. El caballero de Dulcinea ascendió cada vez más en mi estima, ganándose mi amor, en la medida en que yo avanzaba en la lectura del maravilloso libro, lo que hacía a diario en aquellos jardines, de modo que ya en otoño llegué al final de la historia... ¡ Y nunca olvidaré el día en que leí lo del lastimoso duelo donde el hidalgo sucumbió de manera tan ignominiosa! (HHSS 4: 152).

Heine se preguntaba a continuación qué debate interno con el Quijote había tenido lugar en él desde aquella primera reacción infantil. Con su proverbial subjetivismo postromántico desplicga ante el lector toda la gama de la cambiante recepción que él hizo de esta novela según su propio grado de madurez:

¿Acaso mi corazón ha quedado estable todo este tiempo o más bien ha vuelto, tras una singular trayectoria, a los sentimientos de la infancia? Posiblemente sea cierto lo último: porque me acuerdo de haber leído el Quijote, en cada lustro de mi vida, con una variedad de sensaciones alternándose. Cuando

5.- Joaquín Casalduero, en su edición del Quijote (Madrid, Alianza Editorial, 1984: 62), observa en una nota a pie de página, refiriéndose al "juego entre la visión inimaginable y la elemental captación de la realidad", que "a partir de ahora tenemos que estar atentos continuamente a esa doble tangencia del espíritu humano". 


\section{UNA MIRADA POÉTICA SOBRE EL NACIMIENTO DE LA NOVELA}

florecí como adolescente, agarrando con manos inexpertas los rosales de la vida y trepando hacia las peñas más altas para estar más cerca del sol, y no soñando con otra cosa por la noche que con águilas y vírgenes puras, el Quijote cra para mí un libro muy fastidioso, y cuando me cerraba el paso, lo apartaba con malhumor. Más tarde, cuando me hice hombre, me reconcilié bastante con el desafortunado paladín de Dulcinea y empecé a reírme de él. Este tío es un necio, me decía. Pero curiosamente, en todos los viajes de mi vida me perseguían las sombras chinescas del flaco hidalgo y su gordo escudero, sobre todo cuando yo llegaba a una encrucijada crítica. Por ejemplo, me acuerdo de haberme despertado en el coche, una mañana durante mi viaje a Francia, de un febril duermevela y haber visto en la bruma matutina cabalgar a mi lado dos figuras conocidas, de las que una, a mi derecha, cra Don Quijote de la Mancha montado en su abstracto Rocinante, y la otra, a mi izquierda, era Sancho Panza sobre su positivo asno. Acabábamos de llegar a la frontera francesa. El noble manchego inclinó respetuosamente la cabeza ante la bandera tricolor que nos saludaba desde lo alto de un poste fronterizo; el buen Sancho saludó con un gesto algo más frío a los primeros gendarmes franceses que aparecieron cerca de allí; por fin ambos amigos se me adelantaron, les perdí de vista y sólo oía de vez en cuando los relinchos entusiastas de Rocinante y los rebuznos afirmativos del asno (HHSS 4: 153).

Heine suscribía plenamente el procedimiento irónico de Cervantes, recurso que él también había adoptado para sus poesías y prosas más combativas y que era una de sus máscaras o caparazón contra la nefasta situación política reinante en Alemania. Ya adulto, la lucha contra los imposibles significaba para Heine un necesario esfuerzo del escritor contra las circunstancias adversas de su tiempo. Según opina Ritchie Robertson acerca del prólogo de Heine:

He suggests that one cannot do without profound beliefs, even if, like don Quixote's, they are delusions and lead to humiliation. In supporting the cause of freedom in a reactionary world, is he himself not tilting at windmills, exposing himself to misfortunes as unnecessary as Don Quixote's? Nevertheless, he decides that it is more honourable to fight quixotically for freedom than to accept the mundane disillusionment of Sancho Panza (Robertson 1988: 91).

En De l'Allemagne, título de sendas ediciones de 1835 y 1855 que contenían colecciones de ensayos sobre Alemania redactados en francés, Heine ya había confesado su admiración por Cervantes en los siguientes términos: «Cervantes [...] exerce sur moi un charme indéfinissable. Je l'aime jusqu'aux larmes. Cet amour date de très longtemps» (HHSS 3: 878). Debió de sentir esa empatía por identificar su trayectoria vital con la de su alocado / cuerdo héroe Alonso Quijano.

Con los años, Heine se había convertido de lector ingenuo en crítico sagaz y pudo contar, además de con sus propios criterios, con las interpretaciones alegóricas que de Don Quijote y Sancho Panza habían hecho tiempo atrás Jean Paul y August Wilhelm Schlegel ${ }^{6}$. Por otra parte, los detalles biográficos sobre Cervantes los tomó de la Notice de Viardot previa a su versión francesa (Cervantes 1837: XII). Ahora bien, la aportación personal de Heine consiste en haber aplicado el filtro del subjetivismo típico de un genio de la expresión literaria y, por más señas, por su condición de "último pocta romántico» que -según escribiría en sus "Confesiones" de 1854 había «culminado y superado el romanticismo y sentado las bases de la lírica moderna» (HHSS 6/II: 447). Privilegiemos, pues, al propio Heine que es quien nos da la mejor explicación de esa eterna dicotomía que su tiempo le hizo sentir en carne viva:

[...] Me parecía entonces que la ridiculez del quijotismo consistía en que el noble hidalgo quería resucitar un pasado, desde hacía tiempo caduco, y sus pobres miembros, especialmente su espalda, entraban en doloroso roce con los hechos del presente. $\mathrm{A}$ h, desde entonces soy consciente de que es locura igualmente ingrata si uno pretende introducir el futuro con excesiva premura en el presente y sólo posee, para esta lucha contra los intereses del día, un jamelgo muy flaco, una armadura muy maltrecha y un cuerpo igualmente frágil! (HHSS 4: 153-154).

6.- Jean Paul Friedrich Richter, Vorschule der Ästhetik (ed. N. Miller) Múnich: Hanser, 1963: 126 y A. W. Schlegel, Sämmtliche Werke I, (ed. E. Böcking), Hildesheim / New York, 1971: 342. 


\section{BERIT BALZER}

Como brillante polemista comprometido con las luchas democráticas de su tiempo, Heine pasaba a menudo de un ardiente entusiasmo a la más negra desesperación. Como artista, su precario cometido fue iniciar una nueva época de las letras, es decir, «introducir el futuro con excesiva premura en el presente» (véase la cita precedente) mediante las armas de la ironía y de elementos deliberadamente prosaicos. En su opinión, el verdadero genio era aquel que cerraba y superaba una época y una moda:

¿Qué idea fundamental guió al gran Cervantes cuando escribió su gran libro? ¿Tan sólo quiso acabar con las novelas de caballería, cuya lectura causaba tantos estragos en la España de su tiempo que nada pudieron contra esta moda ni los decretos mundanos ni los eclesiásticos? ¿O quiso ridiculizar todas las manifestaciones del entusiasmo humano en general, comenzando por el heró́smo de los espadachines? Por lo visto sólo se proponía una sátira contra las mencionadas novelas, a las cuales, iluminando sus absurdidades, quiso someter a la burla de la gente para hundirlas. Y lo consiguió espléndidamente: lo que no lograron ni las amonestaciones desde el púlpito ni las amenazas de los abogados, lo consiguió un pobre escritor con su pluma: Destruyó tan radicalmente las novelas de caballería que al poco tiempo tras la aparición del Quijote se extinguió el gusto por aquellos libros en toda España y ya no se imprimió ninguno. Pero la pluma de un genio siempre es mayor que él mismo; siempre abarca mucho más que sus intenciones temporales, y sin ser del todo consciente de cllo Cervantes escribió la mayor sátira contra el entusiasmo humano (HHSS 4: 154).

Heine lo tenía claro: «Hay que buscar la historia de los poetas en sus obras y allí encontrarás sus confesiones más íntimas» (HHSS 4: 156). Lo mismo podría decirse, naturalmente, de su propia respuesta al estímulo cervantino. De ahí que la siguiente reflexión parezca en el fondo un autoanálisis:

Pero, ¿acaso la desgracia del genio es siempre obra únicamente de una ciega casualidad, o nace, al contrario, por necesidad de su naturaleza íntima y la de su entorno? ¿Es su alma la que libra una batalla con la realidad, o es la cruda realidad la que emprende una lucha desigual con su noble alma? (HHSS 4: 158).

La entonces polémica defensa de Heine de una élite intelectual está en la línea de su elogio de Cervantes y Shakespeare, para él cumbres artísticas en sus países a quienes la monarquía y la doctrina religiosa les brindaba un sistema protector. Las ideas republicanas de igualdad, muy difundidas entre los círculos progresistas en los años treinta del siglo XIX, estaban en flagrante contradicción con esta concepción heineana del artista:

[...] aquel que, a través de la fuerza invencible del genio, destaca sobre una banal mediocridad [y] será objeto del ostracismo de la sociedad que le persigue con tan implacables escarnios y difamaciones que finalmente tendrá que retirarse a la soledad de sus pensamientos (HHSS 4: 158).

Heine calibró la talla de soldado de Cervantes y supo delimitar con gran perspicacia la posición ideológica de éste en la época que le tocó vivir. Estableció asimismo paralelismos con Shakespeare en cuanto a vivencias:

[... ambos autores no son sólo la flor de su tiempo, sino que fueron también la raíz del futuro. $\mathrm{Al}$ igual que ha de verse a Shakespeare, por la influencia que sus obras ejercieron en Alemania y en la Francia de hoy, como fundador del posterior arte dramático, debemos venerar a Cervantes como fundador de la novela moderna (HHSS 4: 159-160).

Heine era consciente del papel fundamental que Cervantes iba a jugar en el posterior desarrollo de la novela moderna y formulaba con exactitud el afán realista que contenía esa nueva manera de narrar y que iba a ser tomada como punto de referencia ineludible por los grandes novelistas europeos del siglo XIX:

Esas novelas de caballería, que degeneraban de la manera más absurda, fueron derrocadas por Cervantes con su Don Quijote. Pero escribiendo una sátira que acababa con la novela más antigua, él mismo proporcionó el modelo para una nueva forma de escribir que llamamos la novela moderna. Ésta es la manera de proceder 


\title{
UNA MIRADA POÉTICA SOBRE EL NACIMIENTO DE LA NOVELA
}

\begin{abstract}
de los grandes poetas: fundan algo nuevo destruyendo lo viejo; nunca niegan nada sin afirmar algo. Cervantes fundó la novela moderna introduciendo en la novela de caballerías el fiel retrato de las clases bajas, agregándole la vida del pueblo. Describir las inclinaciones y los quehaceres del populacho más vulgar, de la chusma más abyecta, no es propio sólo de Cervantes sino de todos los literatos contemporáncos suyos y lo encontramos tanto en los escritores como en los pintores de la España de entonces. Un Murillo? que robó al cielo sus colores más sagrados, pintando con ellos a sus más bellas vírgenes, retrató con el mismo amor a los tipos más sucios de esta tierra. Quizás fue el propio entusiasmo por el arte el que hacía que esos nobles españoles sintieran el mismo placer ante el retrato de un niño mendigo que se espulga como ante la representación de la Santísima Virgen. O fue el encanto del contraste el que impulsó a los hidalgos más nobles - un cortesano de veinticinco alfileres como Quevedo o un poderoso ministro como Mendoza- a escribir sus novelas de mendigos y pícaros harapientos. A lo mejor querían trasladarse mediante la fantasía de la monotonía de su entorno estamental a la esfera social opuesta, según hallamos esta misma necesidad en algunos escritores alemanes que llenan sus novelas exclusivamente de descripciones del mundo aristocrático y siempre convierten a sus héroes en condes y barones. En Cervantes todavía no encontramos esa dirección unilateral de representar lo innoble por separado; tan sólo mezcla to ideal con lo vulgar, una cosa sirve a la otra para echar una sombra o para iluminar, y el elemento aristocrático tiene tanta fuerza como el popular. Pero este elemento hidalgo, caballeresco, aristocrático desaparece por completo en la novela de los ingleses, que fueron los primeros en imitar a Cervantes y hasta hoy día siempre le toman por modelo (HHSS 4: 160-161).
\end{abstract}

El que «desaparezca por completo el elemento aristocrático» empañaba para Heine la calidad de la obra de arte. De ahí que abogara por mantener, aunque fuese como elemento de contraste, el "clemento aristocrático". Continuando en esta vena, tampoco lc fue difícil hacer la siguiente distribución "nacionalista" por géneros literarios: «[...] A los españoles les corresponde la fama de haber producido la mejor novela, como hay que atribuir a los ingleses la fama de haber logrado lo máximo en el terreno dramático» (HHSS 4: 163). Adjudicaba así a Cervantes el mérito de haber sentado la base de la novelística curopea que llegaría a su máxima expresión con el realismo del siglo XIX. Heine, muerto en 1856, ya no pudo ser testigo de la culminación de este género literario del que rastreaba un esplendoroso nacimiento en el Quijote.

Ahora bien, para el gusto de Heine, en poesía nadie superaba a su compatriota Goethe del que, por cierto, se consideraba el más digno émulo: "Cervantes, Shakespeare y Goethe forman el triunvirato que en los tres géneros literarios, el épico, el dramático y el lírico, ha producido lo máximo» (HHSS 4: 163). Pero de nuevo hace Heine la siguiente salvedad sobre lo que es la obra de un genio de verdad:

[...] $\mathrm{Al}$ adscribir al mencionado triunvirato los máximos logros en el drama, la novela y la canción quedo lejos de censurar el valor de otros grandes escritores. Nada hay más sandio que la pregunta de qué poeta es mejor que otro. Una llama es una llama, y su peso no puede determinarse por libras y onzas. Ś́lo una vulgar mente de tendero traerá su mezquina báscula de queso para pesar al genio. No sólo los antiguos sino también algunos escritores recientes han producido obras en las que arde la llama de la poesía tan espléndidamente como en las obras maestras de Shakespeare, Cervantes y Goethe. (HHSS 4: 164).

Heine tenía un infalible instinto que reconocía el genio artístico bajo cualquier disfraz o forma externa. No llegó nunca a realizar su viejo sueño de viajar a España -lo más cerca que llegó fue a Cauterets, balneario del Pirineo francés-, pero era un ávido lector de todo lo hispano ${ }^{8}$. Aunque nada o poco conociera de las costumbres españolas del Siglo de Oro, supo ver que con el Quijote llevaba entre manos un grandioso producto del espíritu humano. Quizás uno de los comentarios más reveladores de Heine acerca de la técnica cervantina -que es en definitiva lo que más nos interesa en cl marco del presente trabajo- sea el pasaje siguiente:

7.- Heine había visto los cuadros "Niños comiendo fruta" y "Niño mendigo espulgándose" de Bartolomé Esteban Murillo en la Vieja Pinacoteca de Múnich.

8.- Véase mi artículo "Spain in Heine-Heine in Spain. Notes on a bilateral reception", en: Kent / Wolber / Hewitt (eds.), The Lion and the Eagle. Nueva York y Oxford: Berghahn Books 2000: 214-234. 


\section{BERIT BALZER}

[... | quisiera llamar la atención sobre la forma de su novela en general y las dos figuras que ocupan su centro.

Don Quijote y Sancho Panza [...] se parodian constantemente y sin embargo se complementan tan maravillosamente que configuran al verdadero héroe de la novela, ellos atestiguan el sentido artístico del autor a la vez que su profundidad espiritual. Cuando otros autores, cuyos héroes viajan por el mundo en solitario, tienen que recurrir a monólogos, cartas o diarios para dar a conocer los pensamientos y sentimientos del héroe, Cervantes puede hacer prevalecer en todas partes un diálogo natural; $y$ al parodiar siempre un personaje el discurso del otro, la intención del autor sobresale con mayor nitidez. Desde entonces se ha imitado muchas veces esta doble figura que otorga a la novela de Cervantes una naturalidad tan artística y de cuyo carácter se despliega, como desde un único núcleo, toda la novela con su follaje silvestre, sus flores olorosas, frutos brillantes y monos y pájaros fabulosos que se mecen sobre sus ramas, lo mismo que un gigantesco árbol de la India (HHSS 4: 164-165).

A pesar de los ecos románticos de tales valoraciones, no dejan de ser certeras por la belleza de la imagen evocada y por el símil que establecen entre la novela realista y un organismo vivo a modo de un fabuloso árbol que despliega sus ramas. Con respecto al habla de los personajes, Heine apreciaba la técnica empleada por Cervantes para polarizarlos en su caracterización:

Resumiremos el carácter del lenguaje de Don Quijote y Sancho Panza con las siguientes palabras: el primero, cuando habla, siempre parece estar montado en lo alto de su caballo; el último habla como si estuviera sentado encima de su burro bajito (HHSS 4: 167).

Que esas diferencias en el habla fueran patentes en la traducción alemana dice mucho a favor del traductor Ludwig Tieck, quien se esmeró incluso con una adecuada versión de los profusos refranes".

Heine, al final de su prólogo -recordemos que la versión alemana no tenía ilustraciones como la francesa, y las magníficas ilustraciones de Gustavo Doré de 1863, hechas a la edición de Clemencín, no las llegó a conocer Heine- comentó con acierto la dificultad de plasmar en dibujos una visión tan profunda y amplia del universo:

[...] Llama la atención que un libro tan rico en materia pintoresca como el Quijote no haya contado todavía con un pintor que de él hubiera entresacado temas para una serie de cuadros independientes. ¿Acaso el espíritu del libro es demasiado liviano y fantástico como para que los policromos pigmentos no se escapen de la mano del pintor? Yo no creo. Porque el Quijote, por muy ligero y fantástico que sea, se basa en la dura realidad terrena como tenía que ser para poder convertirse en libro popular. ¿Se debe esto quizás al hecho de que detrás de los personajes que nos presenta el autor se esconden unas ideas tan profundas que no pueden reproducirse en el arte plástico, de modo que éste tan sólo sería capaz de representar la apariencia externa, por descollante que sea, pero no su sentido más profundo? Probablemente ésta sea la razón (HHSS 4: 168-169).

«La mayor sátira contra el entusiasmo humano" -así había calificado al Quijote en su prólogodifícilmente podía encerrarse en formas y colores.

Aunque las palabras de tan destacado entusiasta de Cervantes como fue Heine no aporten hoy en día apenas nuevos datos empíricos sobre el Quijote, nos han dejado, sin embargo, constancia de cómo un genio de la pluma supo calibrar la llama de otro genio, mediando dos siglos y distintos contextos culturales entre ambos. Y ello a pesar de que el poeta Heine no desarrollase su quehacer artístico por los mismos derroteros que el padre de la novela moderna. Lo que experimentó fue, en definitiva, más bien una afinidad o sintonía que la influencia del magisterio cervantino -esporádica y anecdótica en Heine, como decíamos más arriba-sobre su propia técnica novelística.

9.- Véase a este respecto el artículo de M. a Jesús Barsanti, inédito hasta la fecha, "Los refranes encadenados de Sancho Panza en el Quijote de Ludwig Tieck" (en prensa en las Actas del V Congreso de la FAGE, celebrado en Alcalá de Henares en septiembre de 2004). 


\section{UNA MIRADA POÉTICA SOBRE EL NACIMIENTO DE LA NOVELA}

\section{BIBLIOGRAFÍA}

Bertrand, J.-J. (1914) : Cervantes et le romantisme allemand, París: Librairie Felix Alcan.

Brüggemann, W. (1958): Cervantes und die Figur des Don Quijote in Kunstanschauung und Dichtung der deutschen Romantik, Münster: Aschendorffsche Verlagsbuchhandlung.

Cervantes Saavedra, M. de (1837): Der sinnreiche Junker Don Quixote von La Mancha. Von Miguel Cervantes de Saavedra. Aus dem Spanischen übersetzt; mit dem Leben von Miguel Cervantes nach Viardot, und einer Einleitung von Heinrich Heine, vol. I, Stuttgart: Verlag der Classiker. Prólogo de Heine en pp. XLV-LXVI.

- (1838): L'ingénieux hidalgo Don Quijotte de la Mancha, par Miguel de Cervantes Saavedra, traducido y anotado por M. Louis Viardot, París: Dubochet.

Heine, H. (1973-): Historisch-kritische Gesamtausgabe der Werke. 16 vols. (ed. M. Windfuhr), Hamburg: Hoffmann und Campe. (En el texto citado como DHA: Düsseldorfer HeineAusgabe).

- (1997): Sämtliche Schriften (7 vols.), Múnich: Deutscher Taschenbuch Verlag. (Citado como HHSS).

Jäger, A. M. (1999): 'Besaß auch in Spanien manch' luftiges Schloss'. Spanien in Heinrich Heines Werk, Stuttgart y Weimar: Metzler.

Mende, F. (1967): “Bekenntnis 1837. Heinrich Heines 'Einleitung zum Don Quixote”, en HeineJahrbuch 6, 46-66.

Robertson, R. (1983): Heine, Nueva York: Grove Press.

Schrader, L. (1990): "Heinrich Heine als Leser des 'Quijote”, en Gössmann / Windfuhr (eds.), Heinrich Heine im Spannungsfeld von Literatur und Wissenschaft, Essen: 173-183. 